\title{
Transcriptional analysis identifies key genes involved in metabolism, fibrosis/tissue repair and the immune response against Fasciola hepatica in sheep liver
}

\author{
Cristian A Alvarez Rojas ${ }^{1 *}$, Brendan RE Ansell², Ross S Hall², Robin B Gasser², Neil D Young ${ }^{2}$, Aaron R Jex ${ }^{2}$ \\ and Jean-Pierre Y Scheerlinck ${ }^{1}$
}

\begin{abstract}
Background: Although fascioliasis has been relatively well studied, little is known about the molecular basis of this disease. This is particularly relevant, considering the very different response that sheep have to Fasciola hepatica relative to cattle. The acute phase of this disease is severe in sheep, whereas chronic fascioliasis is more common in cattle.

Methods: To begin to explore the host-response to Fasciola in sheep and improve the understanding of the host-pathogen interactions during the parasite's migration through liver parenchyma to the bile duct, we used RNA sequencing (RNA-seq) to investigate livers from sheep infected for eight weeks compared with those from uninfected controls.

Results: This study identified 572 and 42 genes that were up- and down-regulated, respectively, in infected livers relative to uninfected controls. Our molecular findings provide significant new insights into the mechanisms linked to metabolism, fibrosis and tissue-repair in sheep, and highlight the relative importance of specific components of immune response pathways, which appear to be driven toward a suppression of inflammation.

Conclusions: This study is, to our knowledge, the first detailed investigation of the transcriptomic responses in the liver tissue of any host to $F$. hepatica infection. It defines the involvement of specific genes associated with the host's metabolism, immune response and tissue repair/regeneration, and highlights an apparent overlapping function of many genes involved in these processes.
\end{abstract}

Keywords: Fasciola hepatica, Fascioliasis, Sheep, Liver, Transcriptomic, Molecular responses in the host

\section{Background}

Fasciola hepatica is a parasitic flatworm (class Trematoda) responsible for liver fluke disease or fascioliasis in various mammals. This parasite occurs mainly in temperate climatic regions, where suitable conditions favour the survival of particular aquatic snails (Lymnaeidae) that act as the intermediate host [1]. Fascioliasis affects livestock, including sheep and cattle, causing major financial losses due to morbidity and mortality [2-5].

\footnotetext{
*Correspondence: alvarezc@unimelb.edu.au

${ }^{1}$ Centre for Animal Biotechnology, Faculty of Veterinary and Agricultural Sciences, The University of Melbourne, Parkville, Victoria 3010, Australia Full list of author information is available at the end of the article
}

Humans can also become infected by $F$. hepatica or $F$. gigantica, with $>90$ million people being at risk of infection worldwide [6]. Despite its impact, this disease remains neglected, in terms of control and research efforts $[7,8]$.

Fasciola hepatica is transmitted to the mammalian host via the ingestion of the infective stages (metacercariae) which are usually encysted on aquatic vegetation. Following passage through the stomach(s) and upon entry to the small intestine, the metacercariae excyst and the newly excysted juveniles (NEJs) penetrate the small intestinal wall, to then migrate through the abdominal cavity in search of the liver. The juveniles penetrate the 
liver capsule and migrate through the parenchyma to the major bile ducts, a process mediated by the secretion of a complex mix of digestive enzymes produced by the parasite, including cathepsins and other cysteine/serine proteases [9-12]. After 6-8 weeks, the immature flukes reach the bile ducts, where they mature to adults and live for years [1].

The severity of fascioliasis is largely influenced by the infectious dose, and the age and immune status/response of the host [3]. The disease is divided into acute (1-6 weeks after infection) and chronic (from 7-8 weeks) phases, each of which has been explored extensively using histopathological methods [13-15]. During the first two weeks of infection in sheep, the liver is usually congested, with fibrous tags on its surface and haemorrhagic tracks in the parenchyma, mainly in the left lobe [3]. Around the fourth to fifth week after infection, the migratory tracks become yellow and are surrounded by haemorrhage. Tissue atrophy may be observed in some lobes, and fibrin tags as well as fibrous/sclerotic scarring (i.e. wound repair/healing) are usually apparent [3]. Between the sixth and eighth weeks of infection, flukes are $6 \mathrm{~mm}$ to $10 \mathrm{~mm}$ in size and tend to localize in the left lobe, while some of them start to enter the bile ducts [3]. At this stage, infected animals might present with anaemia [16], hypoalbuminaemia [17], eosinophilia [18] and/or hypoglycaemia [17]. Fibrosis appears from the fourth week after infection, and gradually increases as healing occurs in older migratory tracks. Upon maturation in the bile duct, adult flukes may persist for several years, causing fibrosis/sclerosis of the duct (being often more pronounced in cattle than sheep) and inappetence, productivity losses and/or failure to thrive $[3,13]$.

Despite extensive research of fascioliasis, little is known about the interactions between $F$. hepatica and its mammalian hosts on a molecular level. Nonetheless, studies of the secreted proteome [19-22] and transcriptome [23] of adult $F$. hepatica have provided some insights into the pathogenesis of fascioliasis. In addition, investigations of major parasite-derived secreted proteins have shown that cathepsins and other secreted proteases $[24,12,25,26,10]$, immunomodulatory/anti-inflammatory proteins, such as thioredoxin peroxidase [27-30] and helminth defence molecules (FhHDM-1) [20,31,32], are intimately involved in the parasite-host interplay. On the other hand, little is known about the impact of Fasciola at the cellular biological and physiological levels. Cellular changes in the infected liver are associated with a disruption of the mitochondrial electron transport chain, and a substantial loss of cytochrome P450 activity and glycogen content in the left lobe [3]. Physiological changes in infected animals can include glycaemia [33], lipidaemia [34], a reduction in plasma ascorbic acid [35] and testosterone catabolism [36] as well as an increase in iron and iron-binding capacity [35], and a variable effect on coagulation [37]. However, the specific molecular mechanisms underpinning these changes are not well understood.

From an immunological perspective, although it has been reported that the host response to Fasciola infection is primarily Th2-driven $[38,39]$, the precise components of the immune system that are activated or potentially suppressed in the host during F. hepatica infection are not known. Similarly, although there is histological evidence of scarring and wound healing in the liver following acute fascioliasis in sheep [3], the key genes involved in this process have not been identified. The availability of the sheep genome [40] now provides an excellent opportunity to explore host responses to Fasciola infection at the molecular level. In the present study, we characterized the sheep response to Fasciola infection by exploring transcriptional changes in the livers of sheep during the early phase of $F$. hepatica infection.

\section{Methods}

\section{Animals and experimental design}

All experiments were approved by the Ethics Committee of the Faculty of Veterinary and Agricultural Sciences of the University of Melbourne. Eight helminth-free lambs ( $<6$ months of age) were housed in raised pens at the animal facility of the University of Melbourne. At two weeks, four animals (the 'infected' group) received a single oral dose of 180 metacercariae of $F$. hepatica purchased from Baldwin Aquatics Inc., USA. Four additional sheep of the same age and genetic background were maintained as controls and kept in a separate, raised pen in the same facility. All feed, water and management practices were consistent for all infected and control sheep throughout the entire study period. Individual sheep were clinically monitored on a weekly basis. A blood sample was obtained from the jugular vein of each animal twice per week to undertake white blood cell (WBC) differential count in blood smears. Eosinophil levels were used to assess the progression of the infection. Fresh faeces (10 g) were collected on alternate days, six weeks after infection, using a sterile collection bag (attached to the rear of the animal), and tested for the presence of helminth eggs using a standard approach [41]. Eight weeks after infection, each animal was euthanized by intravenous injection of pentobarbitone sodium $(172.5 \mathrm{mg} / \mathrm{kg})$ and immediately necropsied. Upon necropsy, multiple $1 \mathrm{~cm}^{3}$ samples containing lesions characteristic of fascioliasis (tracks) were collected from each animal, snap frozen in liquid nitrogen and stored at $-80^{\circ} \mathrm{C}$ until further use for RNA extraction. Some of these samples were fixed in formalin and, stained with haematoxylin and eosin (H\&E) for histopathological examination. Each stained tissue sample 
was examined by microscopy at $400 \times$ magnification, and eosinophils were enumerated in 10 randomly-selected fields of view.

\section{RNA extraction and library preparation}

Total RNA was extracted from $50 \mathrm{mg}$ of fresh-frozen liver tissue by TriPure reagent (Roche Diagnostics), following the manufacturer's instructions, and resuspended in RNAse-free water (Life technologies). Purified RNA was treated with Turbo DNase (Life Technologies). RNA quality was evaluated using a Bioanalyzer 2100 (Agilent, USA); only samples with an RNA quality indicator (RQI) of $\geq 8$ were used for sequencing. Following quality assessment, polyadenylated (polyA+) RNA was purified from $10 \mu \mathrm{g}$ of total RNA from each sample using Sera-Mag oligo (dT) beads (GE Healthcare, USA), fragmented to 300$500 \mathrm{bp}$, reverse-transcribed using random hexamers, end-repaired and adapter-ligated, according to the manufacturer's protocol (Illumina). Ligated products of $\sim 400 \mathrm{bp}$ were excised from agarose and PCR-amplified (15 cycles). Products were purified over a MinElute column (Qiagen) and subjected to paired-end RNA-seq (read length: $125 \mathrm{nt}$ ) using HiSeq 2000 Ilumina (Yourgene Bioscience, Taiwan).

\section{RNA-seq analysis}

Paired-end RNA-seq reads for each sample/replicate were filtered for quality and adapter-trimmed using Trimmomatic software [42] (sliding window: $4 \mathrm{bp}$, leading and trailing: $3 \mathrm{bp}$, minimum read length: $100 \mathrm{bp}$; Phred quality: 25). Filtered reads were subjected to K-mer correction using the program corrector [43]. Data have been deposited in the Sequence Read Archive (SRA) from the National Center for Biotechnology Information (NCBI; Bio Project ID: PRJNA266851). All filtered reads were mapped to the latest assembly of the sheep genome (sheep genome: Oar v3.1, available under GenBank accession code GCA_000298735.1 [40]), and the transcription abundance of each annotated gene (according to the Ensembl [44] annotation for this version available at http://e74.ensembl.org) quantified using the program RSEM [45]. The transcription abundance of each gene in each sample was represented as transcripts per million reads (TPM) [46]. Differentially transcribed genes (DTG) were identified in $\mathrm{R}$ [47] using the NOISeqbio package (Tarazona et al., 2011), incorporating a betweensamples trimmed-mean of M-value (TMM) normalization using a probability of differential expression $(q)=0.9$. In NOISeqbio, q is equivalent to 1-FDR (false discovery rate), where FDR is considered as an adjusted p-value. Genes with TPM value $=0$ were replaced with a value $=0.05(\mathrm{k})$ for NOISeqbio analysis [48]. We then focused on genes differentially transcribed by more or less than 2-fold (i.e., $\geq 2$-fold change in TPM values for at least three replicates per group).

\section{Bioinformatic analyses}

Enriched gene ontology (GO) terms for up- and downregulated genes were assigned using the BinGO plug-in for Cytoscape [49]. Briefly, the Ensemble identification code (ID) of each sheep transcript predicted with reference to the genome was used to obtain the orthologous gene name for each specific transcript in the Homo sapiens genome database (GRCh37.p13) using Biomart [50], as described previously [51]. The gene names obtained were used as input in BinGO with the most updated version (released 10th July 2014) of the human genome annotation as a reference (GO consortium). For DTG clusters, significantly over-represented (i.e. enriched) GO terms within the 'biological process', 'molecular function' and 'cellular component' categories were identified using hyper-geometric mean tests $(\mathrm{p}<0.05$ after FDR correction). Similarly, to discover enriched pathways and protein family hierarchies for up- and downregulated DTGs, close homologues of sheep transcripts were identified in the KEGG database using BLAST [52], using an expected value of $10^{-5}$, from which $\mathrm{K}$ (pathway) and $\mathrm{Br}$ (Brite) terms for each gene were inferred. Fisher hyper-geometric mean tests were then performed to identify significantly enriched KEGG pathways and enzyme hierarchies for DTGs relative to all KEGG-annotated genes [53,54]. In addition to a broad functional characterization of KEGG pathways and GOs, we also investigated the transcriptional abundance of genes with functions previously implicated in liver fibrosis or the host immune responses against helminths.

\section{Results}

\section{Experimental infection}

Over the eight-week experimental infection period, we detected a statistically significant increase in the relative number of eosinophils vs. the total of white blood cells in all infected sheep when compared with uninfected controls (Student's $t$-test; p-value: 0.05). All sheep in the infected group had an eosinophil count exceeding $10 \%$ of the total WBC count (range: 12-39\%) from the fourth week after infection compared with controls which had counts of 3\% (range: $1-5 \%$ ) at the same time point. At no point during the experiment did eosinophil counts in the control sheep exceed the maximum reference level for uninfected sheep ( $10 \%$ of the total WBC [55]). In contrast, from four weeks after infection, at no point did eosinophil counts drop below $10 \%$ of the total WBC count in the infected sheep, with the exception of animal INF-1, which presented an eosinophil count of $4 \%$ at week six (Figure 1A). In the liver, eosinophil numbers from infected animals ranged between 42 and 89 cells per field of view (400×) (Figures $1 B$ and C), whereas no lesions or notable infiltration of eosinophils or other types of WBC were observed in liver 


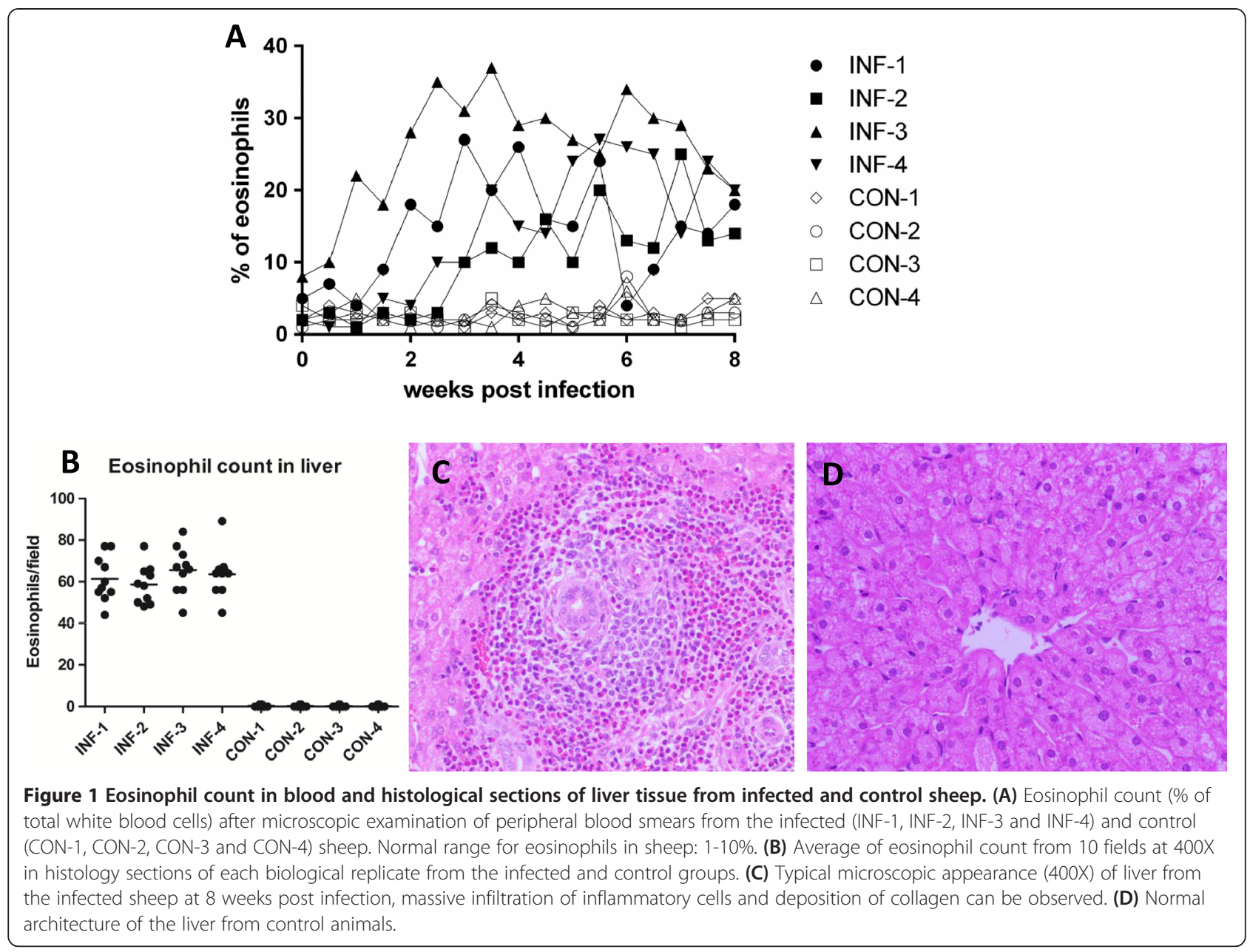

tissue samples collected from uninfected control sheep (Figure 1B and D).

From the sixth week after infection until the end of the experiment, daily faecal examination was conducted on each infected and control animal. No parasite eggs of any species were detected in any animal. The sheep showed no overt clinical signs of infection (e.g., ill thrift, anaemia or weight loss) in either infected or control groups during the experiment. However, upon necropsy, direct examination of the livers showed clear signs of fascioliasis in all infected sheep, including parenchymal tracks characteristic of migrating juvenile parasites and evidence of haemorrhage in several lobes of the liver. Neither comparable pathological signs nor noticeable evidence of damage to the liver tissue was observed in any of the control sheep.

\section{RNA-seq pre-processing, mapping and differential transcription analysis}

After trimming and correction, a total of 82,557,944 RNA-seq paired-end reads were generated from all cDNA libraries (mean of 13.2 million per sample). Alignment rates to the sheep genome ranged from 63.2 to $71.2 \%$ per sample, with an average coverage of $32.2 \mathrm{X}$ (range 13X65.6X) (see Additional file 1). At a lower TPM threshold of 0.05 , the mean transcript detection was 14,091 for the Fasciola-infected sheep (range: 13,413-15,087) and 12,375 for uninfected controls (range: 11,157-13,937). These data allowed differential transcription to be assessed among 12,934 genes in the liver tissue samples, of which 1,012 were differentially transcribed genes in total $(820$ up-regulated and 192 down-regulated in infected relative to control animals). Further refinement of DTGs to select for the most robust transcriptional differences ( $\geq$ twofold difference in TPM values for at least three of four infected sheep relative to the uninfected control mean) retained 572 up-regulated and 42 down-regulated genes representing $4.8 \%$ and $0.24 \%$ of all detected transcripts respectively (see Additional file 2).

\section{Gene ontology and KEGG analysis}

Of the up- and down-regulated genes identified in Fasciola-infected sheep, 492 and 31 were assigned one or more predicted GO term(s) respectively. Of these 
GO terms, 211 and 121 were significantly enriched (hyper-geometric test; FDR $=0.05$ ) within up- and downregulated genes respectively (see Additional file 3). For the down-regulated genes, enriched GO terms related to the molecular function 'oxidoreductase activity' involving cholesterol, flavin, alkane, leukotriene, linoleic and arachidonic acid were overrepresented (Table 1). 'Arachidonic acid binding process' was also overrepresented in up-regulated genes (see Additional file 3: Table S5). For the up-regulated genes, enriched biological process GO terms related to the immune system, including neutrophil aggregation and chemotaxis, regulation of Th2 cell differentiation, regulation of B cell activation; whereas production of $\alpha, \beta$ and type III interferon was overrepresented among down-regulated genes (Table 1). Up-regulated genes also showed enrichment for GO terms in the 'cellular component' category, specifically related to extra cellular matrix (ECM), proteinaceous ECM and collagen type I (Table 1). Importantly, an overrepresentation of $\mathrm{GO}$ terms within the biological process category related to the cell cycle and mitosis was observed among up-regulated genes in infected liver (see Additional file 3: Table S4).
Based on conserved orthologues defined by KEGG, 191 of the up-regulated and 19 of the down-regulated genes identified in the infected animals were assigned to one or more conserved biological pathways. For downregulated genes, we identified an enrichment for KEGG pathways involved in signal transduction (Jak-STAT, TNF, NF-kappa $\beta$ and PI3-Akt signalling pathways), and NF-kappa $\beta$ was also enriched for up-regulated genes (Table 2). For signalling molecules and interactions, the cytokine-cytokine receptor interaction was significantly enriched for up- and down-regulated genes, while ECM-receptor interaction was enriched for up-regulated genes (Table 2). An analysis of up-regulated genes also identified an enrichment of KEGG pathways involved in glycan biosynthesis of chondroitin/dermatan sulphate as well as in the metabolism of lipids (ether lipid, arachidonic acid, linoleic acid and glycerophospholipid) and amino acids (valine, leucine and isoleucine biosynthesis, as well as histidine and glutathione metabolism) (see Additional file 4). For down-regulated genes in infected livers, enriched KEGG pathways were associated with a number of metabolic functions, such as primary bile acid and steroid hormone biosynthesis, arachidonic and linoleic acid

Table 1 Overrepresented Gene ontology (GO) terms for up- $(\uparrow)$ and down- regulated ( $\downarrow$ ) genes in infected liver

\begin{tabular}{|c|c|c|}
\hline Major Function & Transcription & p-value * \\
\hline \multicolumn{3}{|l|}{ Oxidoreductase activity } \\
\hline cholesterol 7-alpha-monooxygenase activity (GO:0008123) & $\downarrow$ & 0.0017 \\
\hline flavin-containing monooxygenase activity (GO:0004499) & $\downarrow$ & 0.0086 \\
\hline leukotriene-B4 20-monooxygenase activity (GO:0050051) & $\downarrow$ & 0.0069 \\
\hline arachidonic acid 11 12-epoxygenase activity (GO:0008405) & $\downarrow$ & 0.0017 \\
\hline arachidonic acid 14 15-epoxygenase activity (GO:0008404) & $\downarrow$ & 0.0017 \\
\hline alkane 1-monooxygenase activity (GO:0018685) & $\downarrow$ & 0.0086 \\
\hline linoleic acid epoxygenase activity (GO:0071614) & $\downarrow$ & 0.0017 \\
\hline \multicolumn{3}{|l|}{ Immune system } \\
\hline neutrophil aggregation (GO:0070488) & $\uparrow$ & 0.0007 \\
\hline neutrophil chemotaxis (GO:0030593) & $\uparrow$ & 0.0004 \\
\hline regulation of T-helper 2 cell differentiation (GO:0045628) & $\uparrow$ & 0.0015 \\
\hline regulation of B cell activation (GO:0050864) & $\uparrow$ & 0.0007 \\
\hline negative regulation of B cell apoptosis (GO:0002903) & $\uparrow$ & 0.0015 \\
\hline cellular response to type I interferon (GO:0071357) & $\downarrow$ & 0.0017 \\
\hline positive regulation of interferon-alpha production (GO:0032727) & $\downarrow$ & 0.0001 \\
\hline positive regulation of interferon-beta production (GO:0032728) & $\downarrow$ & 0.0006 \\
\hline regulation of type III interferon production (GO:0034344) & $\downarrow$ & 0.00001 \\
\hline \multicolumn{3}{|l|}{ Extracellular matrix } \\
\hline collagen type I (GO:0005584) & $\uparrow$ & 0.0007 \\
\hline proteinaceous extracellular matrix (GO:0005578) & $\uparrow$ & 0.0002 \\
\hline extracellular matrix (GO:0031012) & $\uparrow$ & 0.0007 \\
\hline
\end{tabular}

*p-value < 0.05 .

Analysis revealed GO terms related with oxidoreductase ('molecular function'), immune system ('biological processes') and extra cellular matrix ('cellular component'). Full list of GO analyses can be seen in Additional file 3. 
Table 2 Enriched KEGG pathways for up- $(\uparrow)$ and down-regulated $(\downarrow)$ genes in infected liver parenchyma

\begin{tabular}{|c|c|c|c|}
\hline Pathway/ID & Genes & Transcription & p-value * \\
\hline \multicolumn{4}{|l|}{ Signal transduction } \\
\hline Jak-STAT signalling pathway (ko04630) & STAT1, GHR & $\downarrow$ & 0.004 \\
\hline TNF signalling pathway (ko04668) & RPS6KA5 & $\downarrow$ & 0.021 \\
\hline NF-kappa B signalling pathway (ko04064) & DDX58 & $\downarrow$ & 0.025 \\
\hline NF-kappa B signalling pathway (ko04064) & $\begin{array}{l}\text { LAT, CCL4, RELB, TNF, TNFSF14, TLR4, } \\
\text { IGLL1, TICAM1 }\end{array}$ & $\uparrow$ & 0.009 \\
\hline PI3K-Akt signalling pathway (ko04151) & GHR, C-MET & $\downarrow$ & 0.039 \\
\hline \multicolumn{4}{|l|}{ Signalling molecules and interaction } \\
\hline Cytokine-cytokine receptor (ko04060) & TNFSF10, GHR, C-MET & $\downarrow$ & 0.001 \\
\hline Cytokine-cytokine receptor (ko04060) & $\begin{array}{l}\text { CXCR2, ACKR3, INHBA, CCL4, IL1R2, TNF, } \\
\text { TNFSF12, CCL3, TGFB1, PF4, TNFSF14, } \\
\text { CSF3R }\end{array}$ & $\uparrow$ & 0.027 \\
\hline ECM-receptor interaction (ko04512) & OST, COL1A2, THBS2, WWF, COL6A3, HMMR, COL1A1 & $\uparrow$ & 0.007 \\
\hline
\end{tabular}

*p-value $<0.05$.

Analysis revealed KEGG pathways related with signal transduction and signalling molecules and interaction.

Full list of KEGG pathways analyses can be seen in Additional file 4.

metabolism, fatty acid degradation, drug metabolismcytochrome $\mathrm{P} 450$, methane metabolism and oxidative phosphorylation. Notably, a number of KEGG pathways linked to the host immune-system were enriched for down-regulated genes, including RIG-I-like receptor signalling, Cytosolic DNA-sensing and Toll-like receptor signalling (see Additional file 4). However, components of the Toll-like receptor signalling pathway were also found to be enriched in up-regulated genes (see Additional file 4).

KEGG Brite protein families were also enriched, with cytochrome P450, cellular antigens and cytokines as well as enzyme-linked-receptors representing down-regulated genes. For up-regulated genes, enriched Brite protein families included genes relating to 'chromosome' and 'exosome', as well as DNA repair/replication proteins, 'cellular antigens,' 'cytoskeleton proteins', 'cytokines', 'enzymes,' 'lectins,' 'cell adhesion molecules and their ligands', and 'heparan sulphate/heparin binding proteins' (Table 3).

\section{Differential transcription for immune response and liver fibrosis}

Considering the observed link between DTGs associated with infected livers as well as GO terms and KEGG pathways relating to the function and regulation of the host immune system, we specifically queried our differential transcriptional results for genes known to be involved in the Th1, Th2 and Th17 immune responses in mammals (Figure 2). Among the notable genes upregulated in infected sheep were those encoding BCL6 (B-cell CLL/lymphoma 6) and CD86 (immunoglobulin superfamily), IL1R2 (Interleukin 1 Receptor, Type 2), IL18BP (Interleukin 18 Binding Protein), IL27RA (Interleukin 27 Receptor, Alpha), TGFß1 (transforming growth factor-beta 1), TNF (tumour necrosis factor) and TLR4
(Toll-like receptor 4). Although these genes are commonly recognised as markers of a T-cell response, it is not possible to determine the specific nature of the $\mathrm{T}$ cell response with the data presented here. Interestingly, only three interleukins-related genes (receptor and antagonists) were found to be transcribed in this study, namely IL27RA, IL18BP and IL1R2. Finally, we curated DTGs involved in liver tissue damage (i.e. hepatotoxicity) and repair (i.e. ECM formation and fibrosis). In total, eight genes relating to hepatotoxicity, fibrosis and ECM formation were shown to be up-regulated (Figure 3).

\section{Discussion}

In this study, we provide the first comprehensive transcriptomic investigation of sheep livers during $F$. hepatica migration compared with those of uninfected controls, and identify a number of differentially transcribed genes. Each sheep in the 'infected' group had eosinophilia, consistent with that of $F$. hepatica infection for similar time periods in previous reports $[56,57,18]$. Moreover, eight weeks after infection, the livers of infected sheep showed macroscopic lesions which were consistent with those caused by $F$. hepatica [3]. No comparable evidence of parasitic infection was seen in any of the control sheep. Upon RNA-seq analyses, we detected transcription for 15,966 genes, of which 12,934 were sufficiently transcribed to allow the inference of differential transcription between infected and uninfected controls. Current estimates of the numbers of genes transcribed in mammalian tissues, including liver, range from 10,000 to $15,000[58,59]$. Coulouarn et al. [60] identified 12,638 non-redundant transcript clusters in human liver. Our data indicate that we sequenced to a sufficient depth to capture most transcriptional changes in the present study. 
Table 3 Summary of KEGG Brite ontology analysis for up- $(\uparrow)$ and down- regulated $(\downarrow)$ genes in infected liver

\begin{tabular}{|c|c|c|c|}
\hline Brite definition & Brite ID & Transcription & p-value* \\
\hline Cytochrome P450 & ko00199 & $\downarrow$ & 0.00001 \\
\hline Cytokine receptors & ko04050 & $\downarrow$ & 0.0041 \\
\hline Enzyme-linked receptors & ko01020 & $\downarrow$ & 0.0082 \\
\hline Cellular antigens & ko04090 & $\downarrow$ & 0.0492 \\
\hline Chromosome & ko03036 & $\uparrow$ & 0.00000001 \\
\hline DNA repair and recombination proteins & ko03400 & $\uparrow$ & 0.00003 \\
\hline DNA replication proteins & ko03032 & $\uparrow$ & 0.00018 \\
\hline Cellular antigens & ko04090 & $\uparrow$ & 0.00036 \\
\hline Cytoskeleton proteins & ko04812 & $\uparrow$ & 0.00064 \\
\hline Exosome & ko04147 & $\uparrow$ & 0.0074 \\
\hline Cytokines & ko04052 & $\uparrow$ & 0.0088 \\
\hline Enzymes & ko01000 & $\uparrow$ & 0.023 \\
\hline Lectins & ko04091 & $\uparrow$ & 0.034 \\
\hline Cell adhesion molecules and their ligands & ko04516 & $\uparrow$ & 0.037 \\
\hline Heparan sulphate/heparin binding proteins & ko00536 & $\uparrow$ & 0.045 \\
\hline
\end{tabular}

*p-value $<0.05$.

Importantly, this study explores transcription in a small, but representative portion of liver tissue corresponding to macroscopic lesions (linked to fibrosis/ eosinophilia upon histological observation) at a very specific time-point (8 weeks after infection). An interpretation of these differential transcription data needs to consider the difficulties posed by the complexities of the host-parasite relationship and the liver parenchyma itself. The liver plays a central role in the physiology of the host, being responsible for most amino acid, carbohydrate and lipid metabolism, urea synthesis, detoxification, ketogenesis, albumin and glutathione synthesis [61], and it is also an important organ with respect to innate immunity [47]. Liver contains numerous cell types, including sinusoidal endothelial, hepatic stellate (HSC), liver parenchymal (hepatocytes), Kupffer, natural killer and natural killer T cells [62]. It must also be acknowledged that the tissue sections that we have assessed include cells directly interacting with the parasite and those that might have been affected by the pathogen in an indirect manner. The responses of these individual cell populations have thus been combined in our study and represented as 'liver tissue'. As the physiology of the liver is complex, subsequent studies might consider undertaking RNA-seq

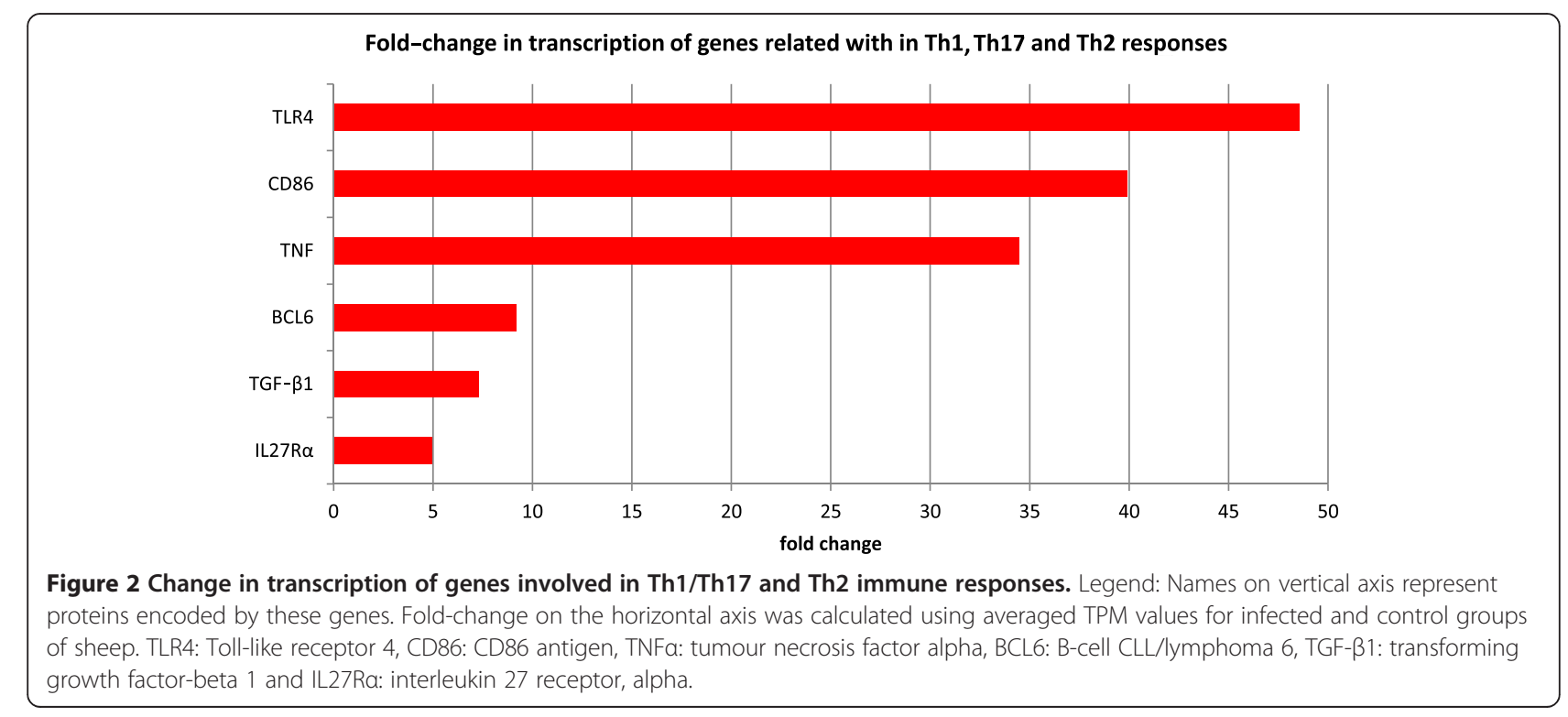


Fold-change in transcrption of genes related with hepatotoxicity, fibrosis and ECM

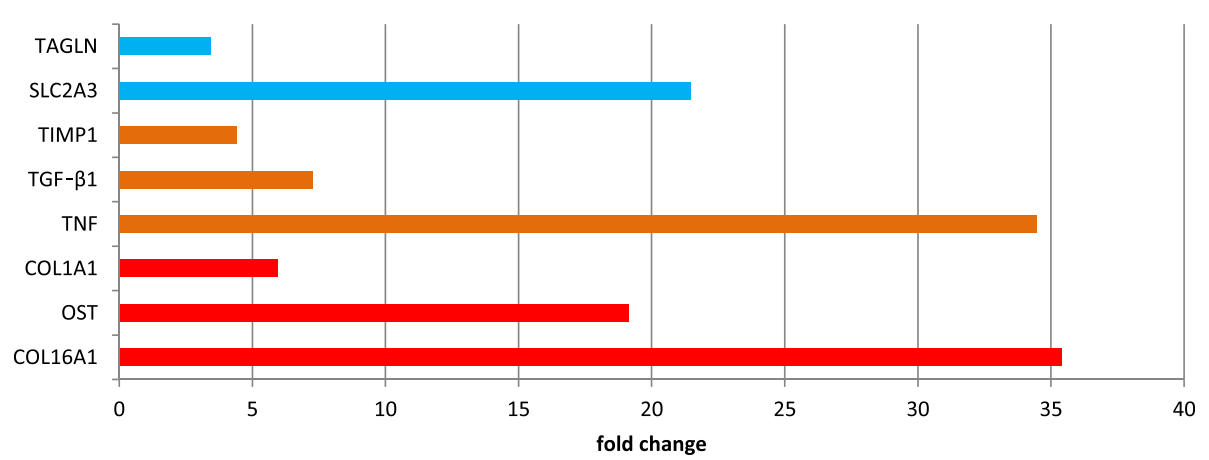

Figure 3 Change in transcription of genes involved in hepatotoxicity (blue bars), fibrosis (orange) and extracellular matrix formation (ECM) (red). Legend: Names on vertical axis represent proteins encoded by these genes. Coloured bars indicate the fold change between TPM values for infected compared with control sheep. Fold-change on the horizontal axis was calculated using averaged TPM values for infected and control groups. TGLN: transgelin, SLC2A3: solute carrier family 2 member 3, TIMP1: tissue inhibitor of metalloproteinases 1, TGF- $\beta$ 1: transforming growth factor beta 1, TNF: tumour necrosis factor, COL1A1: collagen, type I, alpha 1, OST: osteopontin and COL16A1: collagen, type I, alpha 1: collagen, type XVI, alpha 1.

of single cells [63] from populations of individual celltypes sorted by flow cytometer. In addition, although we have presented the data for immune- and fibrosis-related genes in a separate form, it is currently accepted that the immune system acts, in part, through regulating other processes, such as tissue repair and fibrosis [64]. Therefore, some overlap between these two functions might exist for some genes, and the present data cannot ascribe predominance of one function over another. Nonetheless, in assessing the inferred function of these genes, we see a number of key themes, with a significant focus on genes associated with three major functional categories: (a) metabolism, (b) the immune system and (c) response to injury (e.g., liver fibrosis).

Considering the vital role of liver in homeostasis and the overall metabolism of animals, losses in productivity in infected livestock as a consequence of Fasciola infection likely relate, at least in large part, to metabolic perturbation [65]. Behm [3] described a significant reduction in the activity of the mitochondrial electron transport chain in infected compared with uninfected, animals including a loss of cytochrome P450 activity. A number of studies support this finding, showing a reduced capacity to metabolize drugs (a major function of cytochrome $\mathrm{P} 450$ [66]) in livers infected with F. hepatica [67-70]. Consistent with this, in the present study, three genes (cyp7A1, cyp4a11 and cyp2j2) linked to cytochrome $\mathrm{P} 450$ were found to be down-regulated in infected sheep.

We note additional, key changes in the metabolism of infected sheep livers in the present study. KEGG analysis revealed enrichment for genes up-regulated in response to F. hepatica infection of pathways related to lipid, nucleotide, amino acid, carbohydrate and glycan metabolism (see Additional file 4). This finding is consistent with previous haematological studies of Fasciola infection, which have reported changes in glycaemia [33] and lipidaemia [34] in affected animals relative to uninfected controls. A cardinal sign of fascioliasis is anaemia, particularly as a consequence of a large fluke burden, which often significantly affects the health and productivity of animals. Several studies have shown evidence supporting the significant negative effect that Fasciola has on metabolic mechanisms associated iron and iron-binding capacity [35], coagulation [37] and/or various biochemical parameters in blood [71], providing insights into the consequences of and responses to major blood loss in infected animals. In the present study, we infected sheep with a relatively small number $(n=180)$ of metacercariae. Nonetheless, we found a significant increase in the transcriptional abundance of haemoglobin-related genes in infected animals, including haemoglobin subunits $\alpha(h b \alpha), \beta(h b \beta)$ and foetal subunit $\beta(h b \beta f)$ (see Additional file 2). These findings suggest an increased abundance of reticulocytes circulating in infected livers, likely due to blood loss caused by the migrating flukes. Interestingly, the up-regulation of four genes predicted to be involved in Fanconi anaemia (fancc, fancd2, fance and fancf), a rare genetic disorder associated with haematological abnormalities in humans [72], were found in infected livers. To our knowledge, this is the first molecular report of the early response of the host to the blood loss with a low intensity infection.

Immune cells that migrate into the infected liver parenchyma include macrophages, eosinophils, neutrophils and lymphocytes $[73,56,14,74,75]$. The cellular infiltration relates to complex pathways that enable the migration of immune cells from blood to tissues. GO analysis showed 
that amongst the genes differentially up- or downregulated, many were associated with immune mechanisms (Table 2). More specifically, genes involved in the innate immune response and, in particular type I interferon production, were down-regulated. In contrast, we found that genes involved in processes linked to the regulation of Th2 cell differentiation and B-cell activation were up-regulated. It is currently proposed that $F$. hepatica produces a Th2 response or a downregulation of Th1/Th17 that favours the longevity and survival of the parasite in the host animal $[38,39]$. The present results largely support this proposal (Figure 2). Some DTGs, for example $c d 86$ (cluster of differentiation 86 protein) and bcl6 (B-cell lymphoma 6 protein), are classic regulators of a Th2 response [76]. However, some data require careful interpretation and possibly further exploration. For example, we saw a significant upregulation of $\operatorname{tgf}-\beta 1$ and $\operatorname{tnf}$ genes in infected sheep. In mice, TGF- $\beta 1$ promotes the development of Th17 cells $[77,78]$, but at high concentrations, TGF- $\beta 1$ has been shown to promote Fox3p + T-regulatory cells [76], which are anti-inflammatory [79] and a hallmark of many helminth infections [80]. Indeed, the suppression of inflammation is a common theme for many of the immune-related genes that we identified. For example, one of the few interleukins to be shown to be upregulated in the current study (IL18BP) is a natural inhibitor of IFN $\gamma$ and Th1 responses in humans [81] and suppresses inflammation associated with the Th17 response [82]. To our knowledge, this interleukin has not been studied in the interaction between liver flukes and their hosts. IL18BP production is stimulated in response to liver injury, and its increased concentration in serum is linked to the severity of liver damage [83]. Therefore, IL18BP should be explored as a biomarker for liver damage, investigating whether it correlates with the severity of fascioliasis. IL27RA was also upregulated in infected sheep in the current study and is involved in signal transduction in response to IL27, which promotes Th1 differentiation and attenuates immune/inflammatory responses, suppressing Th17 differentiation and IL-17 production [84]. In contrast, TNF $\alpha$ regulates the release of pro-inflammatory cytokines, including IL1 [85] and was also up-regulated. However, intriguingly, one of the few interleukinrelated genes that we found transcribed in the present study is il1r2; the protein encoded by this gene (IL1R2) acts a decoy receptor for IL1R1 and binds IL-1; in so doing, it prevents the release of a number of proinflammatory cytokines [86]. Thus, overall, the immune response in sheep against Fasciola does appear consistent with the 'Th2 promotion and Th1/Th17 suppression' model; however, the mechanisms underpinning this response are complex, potentially contradictory and would benefit from more detailed explorations at the specific cell-type level.

As observed in our histological study and those published in the literature $[56,57,18]$, eosinophils are a major contributor to the cellular immune response against Fasciola in sheep. In the current study, we recorded an up-regulation of two galectin-9 isoforms (ENSOART00000001365 and ENSOART00000017447). One of them corresponds to LGALS9B in the sheep genome, which has been annotated previously as galectin-14 [87], is believed to be an eosinophil-specific galectin in sheep and cattle $[87,88]$, and has been linked to host responses against $F$. hepatica infection [89]. Galectins bind glycans on the surface of potentially pathogenic microorganisms, and function as recognition and effector factors in innate immunity [90]. We found significant changes in transcription associated with the metabolism and biosynthesis of glycans in Fasciola-infected sheep. These changes might be the consequence of a rebalancing of the immune cell-types to achieve a Th2-biased response, with Th1/Th17 and Th2-cells having quite distinct surface glycan profiles [91]. The immune response against parasitic infection is not without implications for the host, particularly in relation to "collateral damage" caused by the induction of oxidative stress via the neutrophil/monocyte respiratory burst. Helminths have developed a number of strategies to counteract the host defences, including through the production of a cocktail of peroxidases and other antioxidant enzymes [92-94]. Host cells also need to deal with reactive oxygen species (ROS) released through respiratory bursts during the host immune response. The up-regulation in infected livers of numerous genes (e.g., $p x d n, i l 18 b p, g p x 3, p r d x 2, h p$, col1a1, ect2, $h b b$ and $a d a)$ specifically involved in neutralizing ROS provides significant insight into the specific mechanisms through which sheep respond to the invading parasite and also the damage that the immune response can cause to host tissues as a consequence.

Many of the genes associated with Fasciola-infection straddle the boundary between stimulating an immune response and repairing tissue damage. For example, TLR4 and another, uncharacterized, TLR-related gene (ENSOART00000020222) were found to be up-regulated in infected tissue. Although, TLR4 is an important component of the innate immune system, it has also been connected with liver injury and hepatic fibrogenesis and other pathologies [95-98]. Additional examples are the up-regulation in infected animals of genes encoding the TGF- $\beta 1$ and its Induced Transcript 1 (TGF- $\beta 111$ ) as well as the chemokines CCL3 and CCL4. In addition to its roles in regulating $\mathrm{T}$-cell differentiation (see above), TGF- $\beta 1$ is also relevant in fibrosis [99-102]. CCL3 and CCL4 are expressed by a number of cell types, including 
activated B cells, monocytes, mast cells, fibroblasts and epithelial cells [103]. CCL3 has also been linked to both liver [104] and lung [105] fibrosis. The up-regulation of genes encoding phagocyte-derived S100s, specifically s100a1, s100a12, s100a8 and s100a9, are also intriguing, because S100 proteins are endogenous activators of innate immune responses that mediate inflammatory responses and recruit inflammatory cells to sites of tissue damage [106,107]. They have also shown to be upregulated in Schistosoma japonicum-induced hepatic granuloma [108] and are specifically linked to wound healing in a variety of tissues, including epidermis [109] and liver [110]. Notably, some of the S100 proteins upregulated in infected livers have been highlighted as playing a key role in wool production in sheep [40]. Studies of sheep fascioliasis [111] have noted a $20-40 \%$ reduction in wool production, even in animals showing no overt signs of disease. Although the present data do not provide information on the transcription/expression of S100s outside of the liver, it is tempting to hypothesize that these S100 proteins are shunted from other tissues (e.g., the epidermis) to the liver in instances of trauma or infection, thus (alongside anaemia and other parasitic effects) effectively sacrificing wool production for liver repair.

The regeneration and repair of the tissue damaged by migrating juvenile $F$. hepatica are key components of the pathogenesis of fascioliasis. Notably, consistent with the high capacity of the liver to regenerate damaged tissue [112], we found a significant up-regulation in infected livers of genes associated with the cell cycle and mitosis (see Additional files 3 and 4). We also noted an

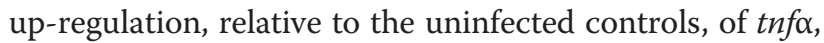
which contributes to the restoration of functional liver mass by driving hepatocyte proliferation and liver regeneration [113].

In addition to regenerating new tissue, the repair of existing liver tissue is critical to host survival. Central to the repair process is fibrosis, collagen deposition and the reformation of the extracellular matrix (ECM). Even at this relatively early stage of fascioliasis, we recorded a significant up-regulation of genes linked to the Jak-STAT pathway, which is known to play a major role in hepatic fibrosis [114]. In addition, we identified an up-regulation of a number of genes involved in these processes in vertebrates (Table 2 and Figure 3). Key examples of upregulated genes linked to fibrosis were homologs of two tgf- $\beta$-related genes, insulin-like growth factor-binding protein-5 (IGFBP-5), calponin, transgelins (tagln and tagln3) and osteopontin (ost/spp1). The role of TGF- $\beta$ in fibrosis is well-documented [115] and mediated by IGFBP-5 [101]. Calponin and transgelins are expressed by hepatic stellate cells (HSCs) during liver fibrosis [116], with HSCs known to switch from vitamin A storage to a myofibroblast-like function in response to liver damage [117]. Calponin is induced in HSCs by TGF- $\beta 1$ during liver fibrosis [118]. Osteopontin has been described as a regulator of T-helper-cell lineage development [119], but also drives fibrosis by promoting HSC activation and ECM deposition [120]. It has been suggested that blocking osteopontin could limit liver fibrosis and represents a potential target for ameliorating the pathogenicity of biliary trematodiases [121].

Key phases of fibrosis are collagen deposition and repair/remodelling of the ECM. In the present study, we found four collagen isoforms (col1a1, col1a2, col16a1 and col6a3) to be up-regulated in infected sheep livers. We also observed an up-regulation of a number of key metalloproteases associated with Fasciola infection, including three disintegrins, four metalloproteinases (two isoforms each of adam8 and adam19) and the genes encoding matrix metalloproteinases MMP19 and TIMP1. Metalloproteinases are ECM-degrading enzymes, often expressed in the liver by HSCs in response to diverse hepatic toxins and/or damage [122,123]. Tissue and ECM remodelling is likely also regulated by serine protease inhibitors, with serpinb8 and serpini1 both upregulated in infected sheep. Serpins are important in a variety of cell types and are up-regulated during injury repair $[124,125]$. In addition to their expression in most (healthy) tissues, they can be found in immune cells [126], highlighting again the dual-function of many of the DTGs identified in this study. Adenosine receptor A2b (adora2b), a key regulator of ECM formation and collagen deposition by fibroblasts [127], was found to be up-regulated. This gene plays a role in blocking liver injury [128], suggesting that it regulates fibrosis in sheep. Considering that fibrosis is often limited in cases of chronic fascioliasis in sheep compared with cattle [3], it would be interesting to confirm the role of $a d o r a 2 b$ during infection by studying its expression in cattle.

\section{Conclusions}

The current study is, to our knowledge, the first detailed investigation of the transcriptomic responses in the liver tissue of any host to F. hepatica infection. This study defines the involvement of specific genes associated with the host's metabolism, immune response and tissue repair/regeneration, and highlights the apparent overlapping function of many of the genes involved in these processes. Of major relevance is the characterization of genes involved in suppressing the Th1/Th17 response (e.g., genes encoding IL18BP and IL27RA), likely contributing to the Th2 biased response against $F$. hepatica infection, widely reported in the literature. Not surprisingly, genes associated with fibrosis and tissue repair, remodelling and regeneration feature prominently among up-regulated genes in the infected animals. The present 
data highlight a role for a number of genes, including tnf- $\alpha$, tgf- $\beta$, calponins, transgelins, osteopontin and $a d o r a 2 b$, associated with these particular functions. Considering the unique manifestation of fascioliasis in cattle compared with sheep, particularly in relation to the extent of the fibrotic response during the chronic stage of infection, detailed exploration of Fasciola-infection of cattle would be highly relevant and would likely provide insight into distinctiveness of disease pathogenesis in these animals. Interestingly, aside from il27ra, $i l 18 b p$ and $i l 1 r 2$, we found no evidence for the transcription of a wide-variety of interleukins in any (control or infected) sheep studied. Their absence from our data might suggest that our approach was not appropriate for their detection, and we thus make no inference regarding their involvement in fascioliasis in sheep at this stage. Although we studied here liver with clear signs of tissue damage linked to the migration of juvenile flukes, it may be that the transcription of many key interleukins and other molecules associated with Fasciola infection in the liver were too localized or ephemeral for detection using the methods employed here. Subsequent studies may benefit from employing laser microdissection and tissue capture [129], targeting tissue(s) in intimate contact with the parasite. Such studies would also allow joint investigations of transcription in the host cells as well as individual parasites in direct contact with each other; this likely represents a powerful approach for elucidating, in great detail, host-parasite interactions. Further studies directed at exploring changes to host transcriptional behaviour over the duration of liver invasion and the establishment of adult Fasciola in the bile duct, for example, by exploring transcription in peripheral blood mononuclear cells (PBMCs) and/or the lymphatic vessels draining the liver, would be highly informative.

\section{Additional files}

Additional file 1: Table S1. Total number of reads per sample from infected and control replicates.

Additional file 2: Table S2. Full list of 572 up-regulated genes in infected liver tissue. Table S3. Full list of 42 down-regulated genes in infected liver tissue.

Additional file 3: Table S4. List of overrepresented GO terms related with "biological Processes" for up-regulated genes in infected liver tissue. Table S5. List of overrepresented GO terms related with "molecular function" for up-regulated genes in infected liver tissue. Table S6. List of overrepresented GO terms related with "Cellular component" for up-regulated genes in infected liver tissue. Table S7. List of overrepresented GO terms related with "biological processes" for down-regulated genes in infected liver tissue. Table S8. List of overrepresented GO terms related with "molecular function" for down-regulated genes in infected liver tissue. Table S9. List of overrepresented GO terms related with "cellular component" for down-regulated genes in infected liver tissue.

Additional file 4: Table S10. List of enriched KEGG pathways for up-regulated genes in infected liver tissue. Table S11. List of enriched KEGG pathways for down-regulated genes in infected liver tissue.

\section{Competing interests}

The authors declare that they have no competing interests.

\section{Authors' contributions}

Conceived and designed the study and supervised the project: ARJ, RBG and JPYS. Undertook the study and data analysis: CAAR, JPYS, RBG and ARJ. Contributed to analysis using various tools: BREA, RSH and NDY. Wrote the paper: CAAR, ARJ and RBG. All authors read and approved the final version of the manuscript.

\section{Acknowledgements}

This work was supported by the Australian Research Council and (ARC) and the National Health and Medical Research Council (NHMRC) of Australia as well as by a Victorian Life Sciences Computation Initiative (VLSCI) grant number VR0007 on its Peak Computing Facility at the University of Melbourne, an initiative of the Victorian Government.

\section{Author details}

${ }^{1}$ Centre for Animal Biotechnology, Faculty of Veterinary and Agricultural Sciences, The University of Melbourne, Parkville, Victoria 3010, Australia. ${ }^{2}$ Faculty of Veterinary and Agricultural Sciences, The University of Melbourne, Parkville, Victoria 3010, Australia.

Received: 28 January 2015 Accepted: 4 February 2015

Published online: 25 February 2015

\section{References}

1. Andrews SJ. The life cycle of Fasciola hepatica. In: Dalton PJ, editor. Fasciolosis. Wallingford, UK: CAB International; 1999. p. 1-20.

2. Kaplan RM. Fasciola hepatica: a review of the economic impact in cattle and considerations for control. Vet Ther. 2001;2:40-50.

3. Behm CA. Pathology, pathophysiology and clinical aspects. In: Dalton JP editor. Fasciolosis. Wallingford, UK: CAB International; 1999. p. 185-217.

4. Schweizer G, Braun U, Deplazes P, Torgerson PR. Estimating the financial losses due to bovine fasciolosis in Switzerland. Vet Rec. 2005;157:188-93.

5. Mezo M, Gonzalez-Warleta M, Castro-Hermida JA, Muino L, Ubeira FM. Association between anti-F. hepatica antibody levels in milk and production losses in dairy cows. Vet Parasitol. 2011;180:237-42. doi:10.1016/j. vetpar.2011.03.009

6. Keiser J, Utzinger J. Emerging foodborne trematodiasis. Emerg Infect Dis. 2005;11:1507-14. doi:10.3201/eid1110.050614.

7. Mas-Coma S, Valero MA, Bargues MD. Chapter 2. Fasciola, lymnaeids and human fascioliasis, with a global overview on disease transmission, epidemiology, evolutionary genetics, molecular epidemiology and control. Adv Parasitol. 2009;69:41-146. doi:10.1016/S0065-308X(09)69002-3.

8. Mas-Coma S. Epidemiology of fascioliasis in human endemic areas. J Helminthol. 2005;79:207-16.

9. Corvo I, O'Donoghue AJ, Pastro L, Pi-Denis N, Eroy-Reveles A, Roche L, et al. Dissecting the active site of the collagenolytic cathepsin $L 3$ protease of the invasive stage of Fasciola hepatica. PLoS Negl Trop Dis. 2013;7:e2269. doi:10.1371/journal.pntd.0002269.

10. Norbury L, Beckham S, Pike RN, Grams R, Spithill TW, Fecondo JV, et al. Adult and juvenile Fasciola cathepsin L proteases: different enzymes for different roles. Biochimie. 2011;93:604-11. doi:10.1016/j.biochi.2010.12.004.

11. Berasain P, Carmona C, Frangione B, Dalton JP, Goni F. Fasciola hepatica: parasite-secreted proteinases degrade all human lgG subclasses: determination of the specific cleavage sites and identification of the immunoglobulin fragments produced. Exp Parasitol. 2000;94:99-110. doi:10.1006/expr.1999.4479

12. McVeigh P, Maule AG, Dalton JP, Robinson MW. Fasciola hepatica virulenceassociated cysteine peptidases: a systems biology perspective. Microbes Infect. 2012;14:301-10. doi:10.1016/j.micinf.2011.11.012.

13. Dow C, Ross JG, Todd JR. The histopathology of Fasciola hepatica infections in sheep. Parasitology. 1968;58:129-35. doi:10.1017/S0031182000073480.

14. Meeusen E, Lee CS, Rickard MD, Brandon MR. Cellular responses during liver fluke infection in sheep and its evasion by the parasite. Parasite Immunol. 1995;17:37-45

15. Rushton B, Murray M. Intrahepatic vascular lesions in experimental and natural ovine fascioliasis. J Pathol. 1978;125:11-6. doi:10.1002/ path.1711250103. 
16. Galtier $P$, Alvinerie M. Pharmacological basis for hepatic drug metabolism in sheep. Vet Res. 1996;27:363-72.

17. Dargie JD, Berry Cl. The hypoalbuminaemia of ovine fascioliasis: the influence of protein intake on the albumin metabolism of infected and of pair-fed control sheep. Int J Parasitol. 1979;9:17-25.

18. Chauvin A, Moreau E, Boulard C. Responses of Fasciola hepatica infected sheep to various infection levels. Vet Res. 2001;32:87-92. doi:10.1051/ vetres:2001113.

19. Wilson RA, Wright JM, de Castro-Borges W, Parker-Manuel SJ, Dowle AA, Ashton PD, et al. Exploring the Fasciola hepatica tegument proteome. Int Parasitol. 2011;41:1347-59. doi:10.1016/j.ijpara.2011.08.003.

20. Robinson MW, Menon R, Donnelly SM, Dalton JP, Ranganathan S. An integrated transcriptomics and proteomics analysis of the secretome of the helminth pathogen Fasciola hepatica: proteins associated with invasion and infection of the mammalian host. Mol Cell Proteomics. 2009:8:1891-907. doi:10.1074/mcp. M900045-MCP200

21. Boukli NM, Delgado B, Ricaurte M, Espino AM. Fasciola hepatica and Schistosoma mansoni: identification of common proteins by comparative proteomic analysis. J Parasitol. 2011;97:852-61. doi:10.1645/ge-2495.1.

22. Hernandez-Gonzalez A, Valero ML, del Pino MS, Oleaga A, Siles-Lucas M. Proteomic analysis of in vitro newly excysted juveniles from Fasciola hepatica. Mol Biochem Parasitol. 2010;172:121-8. doi:10.1016/j. molbiopara.2010.04.003.

23. Young ND, Hall RS, Jex AR, Cantacessi C, Gasser RB. Elucidating the transcriptome of Fasciola hepatica - a key to fundamental and biotechnological discoveries for a neglected parasite. Biotechnol Adv. 2010;28:222-31. doi:10.1016/j.biotechadv.2009.12.003

24. Donnelly S, O'Neill SM, Stack CM, Robinson MW, Turnbull L, Whitchurch C, et al. Helminth cysteine proteases inhibit TRIF-dependent activation of macrophages via degradation of TLR3. J Biol Chem. 2010;285:3383-92. doi:10.1074/jbc.M109.060368.

25. Robinson MW, Corvo I, Jones PM, George AM, Padula MP, To J, et al. Collagenolytic activities of the major secreted cathepsin $L$ peptidases involved in the virulence of the helminth pathogen, Fasciola hepatica. PLoS Negl Trop Dis. 2011;5:e1012. doi:10.1371/journal.pntd.0001012.

26. Stack C, Dalton JP, Robinson MW. The phylogeny, structure and function of trematode cysteine proteases, with particular emphasis on the Fasciola hepatica cathepsin L family. Adv Exp Med Biol. 2011;712:116-35. doi:10.1007/978-1-4419-8414-2_8

27. Donnelly S, O'Neill SM, Sekiya M, Mulcahy G, Dalton JP. Thioredoxin peroxidase secreted by Fasciola hepatica induces the alternative activation of macrophages. Infect Immun. 2005;73:166-73. doi:10.1128/iai. 73.1.166-173.2005.

28. Salazar-Calderon M, Martin-Alonso JM, Ruiz de Eguino AD, Casais R, Marin MS, Parra F. Fasciola hepatica: heterologous expression and functional characterization of a thioredoxin peroxidase. Exp Parasitol. 2000;95:63-70. doi:10.1006/expr.2000.4495

29. Donnelly S, Stack CM, O'Neill SM, Sayed AA, Williams DL, Dalton JP. Helminth 2-Cys peroxiredoxin drives Th2 responses through a mechanism involving alternatively activated macrophages. FASEB J. 2008;22:4022-32. doi:10.1096/fj.08-106278.

30. Robinson MW, Hutchinson AT, Dalton JP, Donnelly S. Peroxiredoxin: a central player in immune modulation. Parasite Immunol. 2010;32:305-13. doi:10.1111/j.1365-3024.2010.01201.x.

31. Robinson MW, Donnelly S, Hutchinson AT, To J, Taylor NL, Norton RS, et al. A family of helminth molecules that modulate innate cell responses via molecular mimicry of host antimicrobial peptides. PLoS Pathog. 2011;7: e1002042. doi:10.1371/journal.ppat.1002042.

32. Robinson MW, Alvarado R, To J, Hutchinson AT, Dowdell SN, Lund M, et al. A helminth cathelicidin-like protein suppresses antigen processing and presentation in macrophages via inhibition of lysosomal vATPase. FASEB J. 2012;26:4614-27. doi:10.1096/fj.12-213876.

33. Phiri IK, Phiri AM, Harrison LJ. The serum glucose and beta-hydroxybutyrate levels in sheep with experimental Fasciola hepatica and Fasciola gigantica infection. Vet Parasitol. 2007;143:287-93. doi:10.1016/j.vetpar.2006.09.001.

34. Kozat S, Denizhan V. Glucose, lipid, and lipoprotein levels in sheep naturally infected with Fasciola hepatica. J Parasitol. 2010;96:657-9. doi:10.1645/ge-2104.1.

35. Gameel AA. Fasciola hepatica: plasma ascorbic acid, plasma iron and ironbinding capacity in experimentally infected sheep. Z Parasitenkd. 1982:68:185-9.
36. Fleming MW, Fetterer $\mathrm{RH}$. Peripheral androgen levels in peripuberal rams infected with Fasciola hepatica. Vet Parasitol. 1986;19:295-9.

37. Joachim A, Ali SF, Daugschies A. Fasciola hepatica alters coagulation parameters in sheep plasma in vivo and in vitro. Parasitol Res. 2003;89:53-8. doi:10.1007/s00436-002-0723-3.

38. O'Neill SM, Brady MT, Callanan JJ, Mulcahy G, Joyce P, Mills KH, et al. Fasciola hepatica infection downregulates Th1 responses in mice. Parasite Immunol. 2000:22:147-55.

39. Dalton JP, Robinson MW, Mulcahy G, O'Neill SM, Donnelly S. Immunomodulatory molecules of Fasciola hepatica: candidates for both vaccine and immunotherapeutic development. Vet Parasitol. 2013;195:272-85. doi:10.1016/j.vetpar.2013.04.008.

40. Jiang Y, Xie M, Chen W, Talbot R, Maddox JF, Faraut T, et al. The sheep genome illuminates biology of the rumen and lipid metabolism. Science. 2014:344:1168-73. doi:10.1126/science.1252806.

41. Sewell MM, Hammond JA. The detection of Fasciola eggs in faeces. Vet Rec. 1972;90:510-1.

42. Lohse M, Bolger AM, Nagel A, Fernie AR, Lunn JE, Stitt M, et al. RobiNA: a user-friendly, integrated software solution for RNA-Seq-based transcriptomics. Nucleic Acids Res. 2012;40:W622-7. doi:10.1093/nar/gks540.

43. Brown C, Howe A, Zhang Q, Pyrkosz A, Brom T. A Reference-Free Algorithm for Computational Normalization of Shotgun Sequencing Data. Available at: http://arxiv.org/abs/1203.4802v2. 2012

44. Flicek P, Amode MR, Barrell D, Beal K, Billis K, Brent S, et al. Ensembl 2014. Nucleic Acids Res. 2014;42:D749-55. doi:10.1093/nar/gkt1196.

45. Li B, Dewey C. RSEM: accurate transcript quantification from RNA-Seq data with or without a reference genome. BMC Bioinformatics. 2011;12:323.

46. Wagner GP, Kin K, Lynch VJ. Measurement of mRNA abundance using RNA-seq data: RPKM measure is inconsistent among samples. Theory Biosci. 2012;131:281-5. doi:10.1007/s12064-012-0162-3.

47. Team RC. A language and environment for statistical computing. 2012 http://www.R-project.org/.

48. Tarazona S, Garcia-Alcalde F, Dopazo J, Ferrer A, Conesa A. Differential expression in RNA-seq: a matter of depth. Genome Res. 2011;21:2213-23. doi:10.1101/gr.124321.111.

49. Maere S, Heymans K, Kuiper M. BiNGO: a Cytoscape plugin to assess overrepresentation of gene ontology categories in biological networks. Bioinformatics. 2005;21:3448-9. doi:10.1093/bioinformatics/bti551.

50. Haider S, Ballester B, Smedley D, Zhang J, Rice P, Kasprzyk A. BioMart Central Portal-unified access to biological data. Nucleic Acids Res. 2009;37:W23-7. doi:10.1093/nar/gkp265.

51. Jager M, Ott CE, Grunhagen J, Hecht J, Schell H, Mundlos S, et al. Composite transcriptome assembly of RNA-seq data in a sheep model for delayed bone healing. BMC Genomics. 2011;12:158. doi:10.1186/1471-2164-12-158.

52. Altschul SF, Gish W, Miller W, Myers EW, Lipman DJ. Basic local alignment search tool. J Mol Biol. 1990;215:403-10. doi:10.1016/s0022-2836(05)80360-2.

53. Kanehisa M, Goto S. KEGG: Kyoto encyclopedia of genes and genomes. Nucleic Acids Res. 2000;28:27-30.

54. Kanehisa M, Goto S, Sato Y, Furumichi M, Tanabe M. KEGG for integration and interpretation of large-scale molecular data sets. Nucleic Acids Res. 2012;40:D109-14. doi:10.1093/nar/gkr988.

55. Weiss DJ, Wardrop KJ. Schalm's Veterinary Hematology. Ames, IA: Wiley; 2011.

56. Chauvin A, Bouvet G, Boulard C. Humoral and cellular immune responses to Fasciola hepatica experimental primary and secondary infection in sheep. Int J Parasitol. 1995;25:1227-41.

57. Raadsma HW, Kingsford NM, Suharyanta, Spithill TW, Piedrafita D. Host responses during experimental infection with Fasciola gigantica and Fasciola hepatica in Merino sheep II. Development of a predictive index for Fasciola gigantica worm burden. Vet Parasitol. 2008;154:250-61. doi:10.1016/j. vetpar.2008.03.018.

58. Shackel NA, Gorrell MD, McCaughan GW. Gene array analysis and the liver. Hepatology. 2002;36:1313-25. doi:10.1053/jhep.2002.36950.

59. Barton MC, Stivers DN. Microarray analysis of hepatic-regulated gene expression: Specific applications and nonspecific problems. Hepatology. 2002;35:727-9. doi:10.1053/jhep.2002.32145.

60. Coulouarn C, Lefebvre G, Derambure C, Lequerre T, Scotte M, Francois A et al. Altered gene expression in acute systemic inflammation detected by complete coverage of the human liver transcriptome. Hepatology. 2004;39:353-64. doi:10.1002/hep.20052.

61. Arias I, Wolkoff A, Boyer J, Shafritz D, Fausto N, Alter H, et al. The Liver: Biology and Pathobiology. Ames, IA: Wiley; 2009. 
62. Crispe IN. The liver as a lymphoid organ. Annu Rev Immunol. 2009;27:147-63. doi:10.1146/annurev.immunol.021908.132629.

63. Tang F, Barbacioru C, Nordman E, Li B, Xu N, Bashkirov VI, et al. RNA-Seq analysis to capture the transcriptome landscape of a single cell. Nat Protocols. 2010;5:516-35.

64. Pellicoro A, Ramachandran P, Iredale JP, Fallowfield JA. Liver fibrosis and repair: immune regulation of wound healing in a solid organ. Nat Rev Immunol. 2014;14:181-94. doi:10.1038/nri3623.

65. Lenton LM, Bygrave FL, Behm CA, Boray JC. Fasciola hepatica infection in sheep: changes in liver metabolism. Res Vet Scie. 1996;61:152-6. doi:10.1016/S0034-5288(96)90091-0.

66. Zanger UM, Schwab M. Cytochrome P450 enzymes in drug metabolism: regulation of gene expression, enzyme activities, and impact of genetic variation. Pharmacol Ther. 2013;138:103-41. doi:10.1016/j.pharmthera.2012.12.007.

67. Giorgi M, Salvatori AP, Soldani G, Giusiani M, Longo V, Gervasi PG, et al. Pharmacokinetics and microsomal oxidation of praziquantel and its effects on the P450 system in three-month-old lambs infested by Fasciola hepatica. J Vet Pharmacol Ther. 2001;24:251-9.

68. Tufenkji AE, Alvinerie M, Larrieu G, Houin G, Galtier P. Pharmacokinetics of ampicillin and pentobarbital in the course of subclinical fascioliasis in sheep. Res Vet Sci. 1991;50:75-80.

69. Tufenkji AE, Alvinerie M, Houin G, Galtier P. Pharmacokinetics of sulphobromophthalein, lidocaine and indocyanine green in the course of subclinical fascioliasis in sheep. Res Vet Sci. 1987;43:327-30.

70. Galtier P, Alvinerie M, Plusquellec Y, Tufenkji AE, Houin G. Decrease in albendazole sulphonation during experimental fascioliasis in sheep. Xenobiotica 1991;21:917-24. doi:10.3109/00498259109039531.

71. Matanovic K, Severin K, Martinkovic F, Simpraga M, Janicki Z, Barisic J. Hematological and biochemical changes in organically farmed sheep naturally infected with Fasciola hepatica. Parasitol Res. 2007;101:1657-61. doi:10.1007/s00436-007-0709-2.

72. Kee $Y, D^{\prime}$ Andrea AD. Molecular pathogenesis and clinical management of Fanconi anemia. J Clin Invest. 2012;122:3799-806. doi:10.1172/jci58321.

73. Chauvin A, Boulard C. Local immune response to experimental Fasciola hepatica infection in sheep. Parasite 1996;3:209-15.

74. Sandeman RM, Howell MJ. Response of sheep to challenge infection with Fasciola hepatica. Res Vet Sci. 1981;30:294-7.

75. Zimmerman GL, Kerkvliet NI, Brauner JA, Cerro JE. Modulation of host immune responses by Fasciola hepatica: responses by peripheral lymphocytes to mitogens during liver fluke infections of sheep. J Parasitol. 1983;69:473-7.

76. Hatton RD. TGF-beta in Th17 cell development: the truth is out there. Immunity. 2011;34:288-90. doi:10.1016/j.immuni.2011.03.009.

77. Gutcher I, Donkor MK, Ma Q, Rudensky AY, Flavell RA, Li MO. Autocrine transforming growth factor-beta1 promotes in vivo Th17 cell differentiation. Immunity. 2011;34:396-408. doi:10.1016/.jimmuni.2011.03.005.

78. Li MO, Flavell RA. TGF-beta: a master of all T cell trades. Cell. 2008;134:392-404. doi:10.1016/j.cell.2008.07.025.

79. Shevach EM. Mechanisms of foxp3+ T regulatory cell-mediated suppression. Immunity. 2009;30:636-45. doi:10.1016/j.immuni.2009.04.010.

80. Grainger JR, Smith KA, Hewitson JP, McSorley HJ, Harcus Y, Filbey KJ, et al. Helminth secretions induce de novo T cell Foxp3 expression and regulatory function through the TGF-beta pathway. J Exp Med. 2010;207:2331-41. doi:10.1084/jem.20101074.

81. Novick D, Kim S-H, Fantuzzi G, Reznikov LL, Dinarello CA, Rubinstein M. Interleukin-18 Binding Protein: A Novel Modulator of the Th1 Cytokine Response. Immunity 1999;10:127-36. doi:10.1016/S1074-7613(00)80013-8.

82. Millward JM, Lobner M, Wheeler RD, Owens T. Inflammation in the central nervous system and Th17 responses are inhibited by IFN-gamma-Induced IL-18 binding protein. J Immunol. 2010;185:2458-66. doi:10.4049/jimmunol.0902153.

83. Ludwiczek O, Kaser A, Novick D, Dinarello CA, Rubinstein M, Vogel W, et al. Plasma levels of interleukin-18 and interleukin-18 binding protein are elevated in patients with chronic liver disease. J Clin Immunol. 2002;22:331-7.

84. Yoshida H, Miyazaki Y. Regulation of immune responses by interleukin-27. Immunol Rev. 2008;226:234-47. doi:10.1111/j.1600-065X.2008.00710.x.

85. Lie PP, Cheng CY, Mruk DD. The biology of interleukin-1: emerging concepts in the regulation of the actin cytoskeleton and cell junction dynamics. Cell Mol Life Sci. 2012;69:487-500. doi:10.1007/s00018-011-0760-0.

86. Martin P, Palmer G, Vigne S, Lamacchia C, Rodriguez E, Talabot-Ayer D, et al. Mouse neutrophils express the decoy type 2 interleukin-1 receptor (IL-1R2) constitutively and in acute inflammatory conditions. J Leukoc Biol. 2013;94:791-802. doi:10.1189/jlb.0113035.
87. Dunphy JL, Barcham GJ, Bischof RJ, Young AR, Nash A, Meeusen ENT. Isolation and characterization of a novel eosinophil-specific galectin released into the lungs in response to allergen challenge. J Biol Chem. 2002;277:14916-24. doi:10.1074/jbc.M200214200.

88. Young A, Barcham G, Kemp J, Dunphy J, Nash A, Meeusen E. Functional characterization of an eosinophil-specific galectin, ovine galectin-14. Glycoconj J. 2009;26:423-32. doi:10.1007/s10719-008-9190-0.

89. Young AR, Barcham GJ, McWilliam HE, Piedrafita DM, Meeusen EN. Galectin secretion and binding to adult Fasciola hepatica during chronic liver fluke infection of sheep. Vet Immunol Immunopathol. 2012;145:362-7. doi:10.1016/j.vetimm.2011.12.010.

90. Vasta GR. Roles of galectins in infection. Nat Rev Microbiol. 2009;7:424-38. doi:10.1038/nrmicro2146.

91. van Kooyk Y, Rabinovich GA. Protein-glycan interactions in the control of innate and adaptive immune responses. Nat Immunol. 2008;9:593-601. doi:10.1038/ni.f.203.

92. Hewitson JP, Grainger JR, Maizels RM. Helminth immunoregulation: the role of parasite secreted proteins in modulating host immunity. Mol Biochem Parasitol. 2009;167:1-11. doi:10.1016/j.molbiopara.2009.04.008.

93. Maizels RM, Hewitson JP, Smith KA. Susceptibility and immunity to helminth parasites. Curr Opin Immunol. 2012;24:459-66. doi:10.1016/j.coi.2012.06.003.

94. McSorley HJ, Hewitson JP, Maizels RM. Immunomodulation by helminth parasites: defining mechanisms and mediators. Int J Parasitol. 2013;43:301-10. doi:10.1016/j.ijpara.2012.11.011.

95. Guo J, Friedman SL. Toll-like receptor 4 signaling in liver injury and hepatic fibrogenesis. Fibrogenesis Tissue Repair. 2010;3:21. doi:10.1186/1755-1536-3-21.

96. Liu J, Zhuang ZJ, Bian DX, Ma XJ, Xun YH, Yang WJ, et al. Toll-like receptor-4 signalling in the progression of non-alcoholic fatty liver disease induced by high-fat and high-fructose diet in mice. Clin Exp Pharmacol Physiol. 2014:41:482-8. doi:10.1111/1440-1681.12241.

97. Stifano G, Affandi AJ, Mathes AL, Rice LM, Nakerakanti S, Nazari B, et al. Chronic Toll-like receptor 4 stimulation in skin induces inflammation, macrophage activation, transforming growth factor beta signature gene expression, and fibrosis. Arthritis Res Ther. 2014;16:R136. doi:10.1186/ar4598.

98. Zare-Bidaki M, Tsukiyama-Kohara K, Kazemi Arababadi M. Toll-like receptor 4 and hepatitis B infection: molecular mechanisms and pathogenesis. Viral Immunol. 2014;27(7):321-6 doi:10.1089/vim.2014.0039.

99. Fichtner-Feigl S, Strober W, Kawakami K, Puri RK, Kitani A. IL-13 signaling through the IL-13alpha2 receptor is involved in induction of TGF-beta1 production and fibrosis. Nat Med. 2006;12:99-106. doi:10.1038/nm1332.

100. Palumbo K, Zerr P, Tomcik M, Vollath S, Dees C, Akhmetshina A, et al. The transcription factor JunD mediates transforming growth factor \{beta\}induced fibroblast activation and fibrosis in systemic sclerosis. Ann Rheum Dis. 2011;70:1320-6. doi:10.1136/ard.2010.148296.

101. Sureshbabu A, Okajima H, Yamanaka D, Shastri S, Tonner E, Rae C, et al. IGFBP-5 induces epithelial and fibroblast responses consistent with the fibrotic response. Biochem Soc Trans. 2009:37:882-5. doi:10.1042/bst0370882.

102. Zvibel I, Bar-Zohar D, Kloog Y, Oren R, Reif S. The effect of Ras inhibition on the proliferation, apoptosis and matrix metalloproteases activity in rat hepatic stellate cells. Dig Dis Sci. 2008;53:1048-53. doi:10.1007/ s10620-007-9984-0.

103. Loetscher P, Clark-Lewis I. Agonistic and antagonistic activities of chemokines. J Leukoc Biol. 2001;69:881-4.

104. Heinrichs D, Berres M-L, Nellen A, Fischer P, Scholten D, Trautwein C, et al. The Chemokine CCL3 Promotes Experimental Liver Fibrosis in Mice. PLoS One. 2013;8:e66106. doi:10.1371/journal.pone.0066106.

105. Yang X, Walton W, Cook DN, Hua X, Tilley S, Haskell CA, et al. The chemokine, CCL3, and its receptor, CCR1, mediate thoracic radiation-induced pulmonary fibrosis. Am J Respir Cell Mol Biol. 2011;45:127-35. doi:10.1165/rcmb.2010-0265OC.

106. Foell D, Wittkowski H, Vogl T, Roth J. S100 proteins expressed in phagocytes: a novel group of damage-associated molecular pattern molecules. J Leukoc Biol. 2007;81:28-37. doi:10.1189/jlb.0306170.

107. Goyette J, Geczy CL. Inflammation-associated S100 proteins: new mechanisms that regulate function. Amino Acids 2011:41:821-42. doi:10.1007/s00726-010-0528-0.

108. Chuah C, Jones MK, Burke ML, Owen HC, Anthony BJ, McManus DP, et al. Spatial and temporal transcriptomics of Schistosoma japonicum-induced hepatic granuloma formation reveals novel roles for neutrophils. J Leukoc Biol. 2013;94:353-65. doi:10.1189/jlb.1212653. 
109. Eckert RL, Broome AM, Ruse M, Robinson N, Ryan D, Lee K. S100 proteins in the epidermis. J Invest Dermatol. 2004;123:23-33. doi:10.1111/j.0022202X.2004.22719.X.

110. Demetris AJ, Fontes P, Lunz III JG, Specht S, Murase N, Marcos A, et al. Wound healing in the biliary tree of liver allografts. Cell Transplant. 2006;15:57-65. doi:10.3727/000000006783982386.

111. Roseby FB. The effect of fasciolosis on the wool production of merino sheep. Aust Vet J. 1970;46:361-5.

112. Michalopoulos GK. Liver regeneration. J Cell Physiol. 2007;213:286-300. doi:10.1002/jcp.21172.

113. Schwabe RF, Brenner DA. Mechanisms of Liver Injury. I. TNF-alpha-induced liver injury: role of IKK, JNK, and ROS pathways. Am J Physiol Gastrointest Liver Physiol. 2006;290:G583-9. doi:10.1152/ajpgi.00422.2005.

114. Mair M, Blaas L, Osterreicher CH, Casanova E, Eferl R. JAK-STAT signaling in hepatic fibrosis. Front Biosci (Landmark Ed). 2011;16:2794-811.

115. Gressner AM, Weiskirchen R, Breitkopf K, Dooley S. Roles of TGF-beta in hepatic fibrosis. Front Biosci. 2002:7:d793-807.

116. Molleken C, Sitek B, Henkel C, Poschmann G, Sipos B, Wiese S, et al. Detection of novel biomarkers of liver cirrhosis by proteomic analysis. Hepatology. 2009;49:1257-66. doi:10.1002/hep.22764.

117. Moreira RK. Hepatic stellate cells and liver fibrosis. Arch Pathol Lab Med. 2007:131:1728-34 doi:10.1043/1543-2165.

118. Ueki N, Ohkawa T, Yamamura H, Takahashi K, Tsutsui T, Kawai Y, et al. Induction of calponin-h1 by transforming growth factor-beta1 in cultured human ito cells, L190. Biochim Biophys Acta 1998;1403:28-36.

119. Cantor H, Shinohara ML. Regulation of T-helper-cell lineage development by osteopontin: the inside story. Nat Rev Immunol. 2009;9:137-41.

120. Urtasun R, Lopategi A, George J, Leung TM, Lu Y, Wang X, et al. Osteopontin, an oxidant stress sensitive cytokine, up-regulates collagen-I via integrin alpha(V)beta(3) engagement and PI3K/pAkt/NFkappaB signaling. Hepatology 2012;55:594-608. doi:10.1002/hep.24701.

121. Leung T-M, Wang $X$, Kitamura N, Fiel MI, Nieto N. Osteopontin delays resolution of liver fibrosis. Lab Investig. 2013;93:1082-9. doi:10.1038/ labinvest 2013.104

122. Uemura M, Fujimura Y, Ko S, Matsumoto M, Nakajima Y, Fukui H. Pivotal role of ADAMTS13 function in liver diseases. Int J Hematol. 2010;91:20-9. doi:10.1007/s12185-009-0481-4.

123. Han YP. Matrix metalloproteinases, the pros and cons, in liver fibrosis. J Gastroenterol Hepatol. 2006;21 Suppl 3:S88-91. doi:10.1111/j.14401746.2006.04586.x.

124. Simone TM, Higgins CE, Czekay RP, Law BK, Higgins SP, Archambeault J, et al. SERPINE1: A molecular switch in the proliferation-migration dichotomy in wound-"activated" keratinocytes. Adv Wound Care (New Rochelle). 2014:3:281-90. doi:10.1089/wound.2013.0512

125. Sprecher CA, Morgenstern KA, Mathewes S, Dahlen JR, Schrader SK, Foster DC, et al. Molecular cloning, expression, and partial characterization of two novel members of the ovalbumin family of serine proteinase inhibitors. J Biol Chem. 1995:270:29854-61.

126. Bots M, Medema JP. Serpins in T cell immunity. J Leukoc Biol. 2008;84:1238-47. doi:10.1189/jlb.0208140

127. Feoktistov I, Biaggioni I. Adenosine A2B receptors. Pharmacol Rev. 1997:49:381-402.

128. Smith K. Transplantation: ADORA2B helps to block liver injury. Nat Rev Gastroenterol Hepatol. 2013;10:444. doi:10.1038/nrgastro.2013.129.

129. Fink L, Bohle RM. Laser microdissection and RNA analysis. Methods Mol Biol. 2005;293:167-85

\section{Submit your next manuscript to BioMed Central and take full advantage of:}

- Convenient online submission

- Thorough peer review

- No space constraints or color figure charges

- Immediate publication on acceptance

- Inclusion in PubMed, CAS, Scopus and Google Scholar

- Research which is freely available for redistribution 